\title{
Rapid Transitions: Experiences with Accessibility and Special Education during the COVID-19 Crisis
}

\author{
Emily Long, Sruti Vijaykumar, Serena Gyi and Foad Hamidi * \\ Information Systems, University of Maryland, Baltimore County, Baltimore, MD, United States
}

The ongoing outbreak of the Coronavirus Disease 2019 (COVID-19) and the ensuing preventative lock-down and shelter-in-place policies enacted around the world have caused unanticipated disruptions in the delivery of educational content and accessibility services to children, youth and adults with disabilities. The rapid move to online and remote learning, socialization, and therapeutic activities have surfaced some of the inadequacies of existing systems and infrastructures as well as opportunities for creating novel and accessible solutions. We conducted semi-structured remote interviews with nine special education teachers, therapists, community advocates, and individuals with disabilities to capture their perspectives on delivering services and supporting children and adults with disabilities and their families during the pandemic. Participants shared

OPEN ACCESS

Edited by:

Carlos Duarte,

University of Lisbon, Portugal

Reviewed by:

Sandra Sanchez-Gordon,

Escuela Politécnica Nacional, Ecuador

Francisco Iniesto,

The Open University, United Kingdom

*Correspondence:

Foad Hamid

foadhamidi@umbc.edu

Specialty section:

This article was submitted to

Human-Media Interaction,

a section of the journal

Frontiers in Computer Science

Received: 13 October 2020

Accepted: 16 December 2020

Published: 17 February 2021

Citation:

Long E, Vijaykumar S, Gyi S and Hamidi F (2021) Rapid Transitions: Experiences with Accessibility and

Special Education during the

COVID-19 Crisis.

Front. Comput. Sci. 2:617006.

doi: $10.3389 /$ fcomp.2020.617006 reflections on their experience and those who they serve during the initial phases of the COVID-19 crisis and the challenges and insights that this experience surfaced. Findings include a need to better support families in facilitating remote learning experiences for their children, developing tactile modes of engagement to complement online interactions, and the impact of a lack of contingency plans specifically to support people with disabilities and their families during crizes. The participants also described the lack of clarity about the future as one of the most difficult aspects of the pandemic. We conclude with a discussion of these findings and directions for future research.

Keywords: accessibility, children with disabilities, special education, assistive technology, COVID-19

\section{INTRODUCTION}

The unprecedented scale and speed of the Coronavirus Disease 2019 (COVID-19) pandemic is unique in that the nature of the threat led to government responses mandating social distancing and closure of many institutions and establishments, such as schools, community centers, and businesses deemed nonessential over a prolonged period. Furthermore, the combined isolating nature and prolonged length of the crisis created a need to revert to online remote technologies for accessing localized informational updates to a constantly evolving crisis, participating in key social activities such as learning, receiving and providing professional services, and maintaining quality of life. The rush to adopt online and remote technologies to provide public services, including educational and health services, while effective for individuals and communities who had the technological, societal and economic means to benefit from them, also created barriers for vulnerable populations, including those living with disabilities, low socioeconomic status, or language barriers (Gleason et al., 2020; Kim and Bostwick, 2020). Many concerning news accounts have now emerged on how the impact of the pandemic was amplified by social and economic disparities, causing incredible 
hardship to vulnerable sectors of society, including low-income families, people of color, and older adults, among others (Gleason et al., 2020; Kim and Bostwick, 2020). This adverse impact was also noted by the media in the case of children and adults with disabilities and their families and caregivers (e.g., Shapiro and Harris, 2020). Previously, a number of government reports on the impact of natural disasters and crizes on people with disabilities have underlined the importance of providing multiple forms of communication that recognizes their differing needs and increased vulnerability during crizes (National Council on Disability, 2005; U.S. Department of Justice, Civil Rights Division, 2008; National Council on Disability, 2020). In a more recent report, the United Nations Educational, Scientific and Cultural Organization (UNESCO) pointed out that during the COVID-19 crizes, more time and resources are needed for students with disabilities to participate in learning activities, including access to digital devices, reliable Internet connectivity, and especially designed material and support (States News Service, 2020). These elements may add to the cost of special education for families with children with disabilities during COVID-19. Furthermore, the article pointed out that other factors such as not having access to schoolprovided meals and social interaction with classmates may further negatively impact students with disabilities.

While a small but growing body of research has looked at the experience of people with disabilities during natural crizes (Gjøsæter, et al., 2018; Jagger, 2011; Morris et al., 2014), the scale of the COVID-19 pandemic and its occurrence at a time of unprecedented digital connectivity makes this situation historically unprecedented and an important one to study. The current study documents and analyzes perspectives from professionals and community members in the field during the early phase (first 6 months) of the pandemic's arrival in the United States with a view to inform future efforts to address similar crizes.

In this exploratory project, we conducted semi-structured interviews with special education teachers, learning accessibility coordinators and adult educators with disabilities to understand their perspectives and experience as the pandemic unfolded in the United States during the first half of 2020. The paper's contribution is providing a snapshot of the experience of professionals in the fields of special education and accessibility during the early phases of this unprecedented pandemic, with a view of informing better preparation and planning responses for future crizes. Our research question is what are the perspectives of special education professionals and adult educators with disabilities with using digital technology during the early phases of the COVID-19 pandemic? While we recognize the importance of capturing the views of children with disabilities and their parents during this time as well, in this paper, we decided to focus on professionals tasked to serve these populations to both lessen the burden of participation in research on these families that were already burdened by the pandemic, and to capture a high-level broad view of accessibility at the time of crizes.

In the next section of the paper (Section Related Works: Accessibility and Special Education During Crizes), we provide an overview of the research literature on accessibility and special education during crizes. Next, we describe our methods, including demographic details about participants and data collection and analysis procedures (Section Materials and Methods). Following, we will present the outcome of our analysis in the Findings section (Section Results). This is followed by a Discussion that synthesizes our findings and present key takeaways (Section Discussion). Finally, we conclude and describe future research directions (Section Conclusion).

\section{RELATED WORKS: ACCESSIBILITY AND SPECIAL EDUCATION DURING CRIZES}

There is a small but growing body of research that focuses on the experience of people with disabilities using technology during natural disasters and crizes. In this section, we provide an overview of existing research in this area and identify gaps in the knowledge that our paper addresses.

A considerable body of research has focused on the role of technology during crizes (Hughes and Palen, 2009; Lord, 2010; Dailey and Starbird, 2014; Birnbaum et al., 2015; Gjøsæter et al., 2018). This includes studies of self-organizing during crizes (e.g., Dailey and Starbird, 2014), using social media to share information and resources (e.g., Birnbaum et al., 2015), and studies of crisis management practices e.g., (Lord, 2010; Gjøsæter et al., 2018). In this body of work, a small number of projects have focused on accessibility and the experience of people with disabilities during crizes. In a systematic review of Information and Communication Technology (ICT) design for emergency management systems, Gjøsæter et al. found that the majority of research on systems designed for emergency management did not consider accessibility issues or Universal Design approaches to address these issues (Gjøsæter et al., 2018). Furthermore, they found that there is a lack of communication support for people who are deaf. In the context of Low- and Middle-Income Countries (LMICs), researchers have proposed using a human rights framework to ensure disability inclusion in disaster response (Lord, 2010). While important in identifying an understudied area, these previous works miss first-hand perspectives of people with disabilities and people who work with them during the time of disaster.

Birnbaum et al. identified six temporal phases of a disaster, starting from 1) Pre-event to 6) Recovery (Birnbaum et al., 2015). While the duration and scale of the COVID-19 crizes is unusual, we may map the timing of our interviews to the fourth and fifth phases that correspond to the 4) Functional Damage phase that is still impacting how society deals with the direct consequences of the initial phases of 2) Event and 3) Structural Damage, and 5) Relief phase in which assistance is provided to affected communities (Figure 1). With respect to a prolonged crisis, such as the ongoing COVID-19 pandemic, researchers have described chronic uncertainty as a potential outcome with possible adverse effects on mental health, including anxiety depression, and posttraumatic stress disorder (Palen et al., 2020; Xiong et al., 2020). These previous works have not 


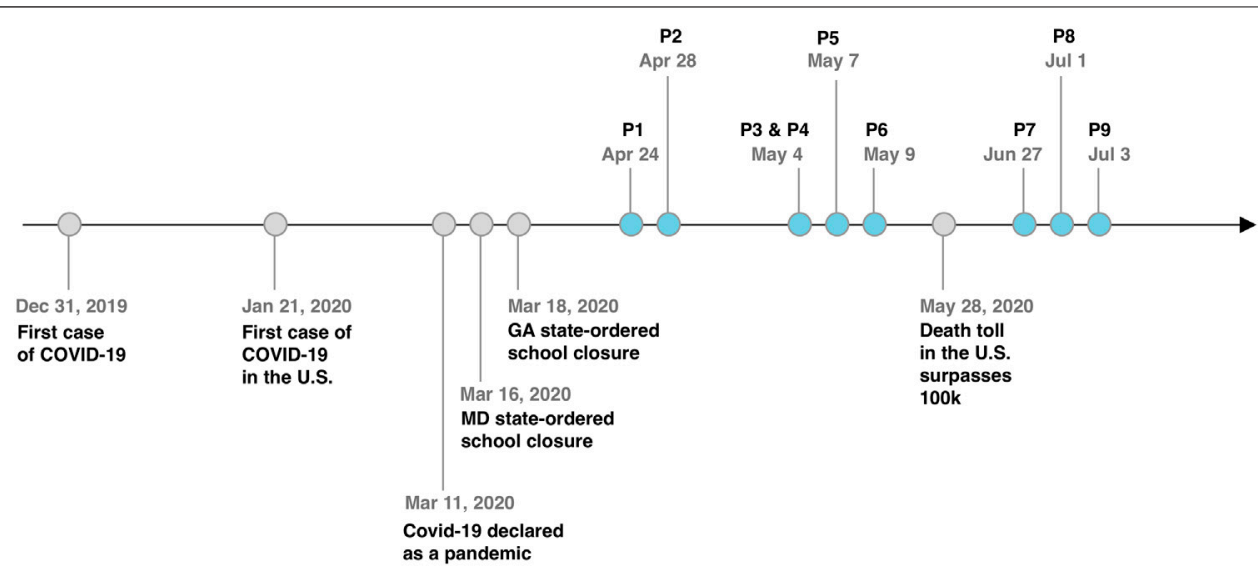

FIGURE 1 | A timeline of interviews and major events related to COVID-19.

shown how these possibilities may impact people with disabilities and their communities differently from the general public.

Research has also documented community-focused emergency preparedness projects that underline the importance of including people with disabilities in emergency planning and providing opportunities for self-advocacy and community-building (Jagger, 2011). These projects have resulted in easy-to-use and low-fi tools and techniques, including designing printed tips for first-responders, printed kits and guides specifically for people with disabilities, and instructions for how to include people with disabilities in emergency planning meetings, to support diverse communities during crizes. These methods are primarily designed for natural and manmade disasters and emergency situations that are short in duration and in a smaller scale. The COVID-19 crisis is different from most previous ones in both of these respects.

A handful of papers have described the experience of people with disabilities during crizes, mostly focusing on people with physical disabilities (Jagger, 2011). For example, Morris et al. studied the use of social media by people with disabilities using a survey with 1,120 participants (Morris et al., 2014). They found that while social media use was generally high for people with disabilities, this use was not continued during emergency situations. Furthermore, they found that younger participants, and those with hearing impairments reported higher levels of use. In another study, Gleason et al. analyzed Twitter data to identify accessibility issues that surfaced during the crizes (Gleason et al., 2020). They found that people with disabilities faced barriers to essential retail services, the abrupt transition to online education exacerbated accessibility issues, and that people with disabilities found public health messaging inconsistent and inaccessible. To our knowledge, the study be Gleason et al. is the only study to date that has focused on the perspectives of people with disabilities during COVID-19 (Gleason et al., 2020). Despite its pioneering importance, Gleason et al.'s work used Twitter data that was not directly collected from participants to inform their research.

Another relevant body of research has focused on understanding and mitigating the accessibility challenges of online and remote learning resources under non-crizes circumstance (Roberts et al., 2011; Al-Mouh et al., 2014; Chatterjee et al., 2017; Iniesto et al., 2019). For example, Roberts et al., found that almost $69 \%$ of students with disabilities who were surveyed kept their disabilities private and $71 \%$ chose to not request accommodations (Roberts et al., 2011). While a number of efforts have resulted in the development of accessibility guidelines specifically for online learning resources (e.g., Al-Mouh et al., 2014; Chatterjee et al., 2017), the accessibility of online learning resources has remained an issue (Iniesto et al., 2019), with research showing that beyond interaction, some features of remote technologies, such as need for sustained screen time or working with a self-imposed schedule, make it hard for students with disabilities to benefit compared to offline learning (Roberts et al., 2011). It is unclear how these results differ at the time of long-term crizes, such as the COVID-19 pandemic.

While previous research has identified both the possibilities and challenges of using technologies to inform, educate and socially include people with disabilities, there is a lack of research that focuses on the shifting perceptions of people who work with or provide services to people with disabilities during an enfolding long-lasting worldwide pandemic, such as the COVID-19 crizes. Additionally, overwhelming reliance on and unprecedented shift to, especially in Western countries, using online and remote technologies have provided conditions that are significantly different from previous crizes and therefore warrant new investigation. In this paper, we contribute to this body of research by presenting the experience and perspectives of special education professionals and adult educators with disabilities with using digital technology during the pandemic.

\section{MATERIALS AND METHODS}

\section{Participants}

Table 1 shows details of our participants. Seven participants were special education professionals. One participant was a caregiver who also works with students with learning disabilities, and one participant was a deaf individual (P5). However, we acknowledge 
TABLE 1 | Participant demographic information (IEP: Individualized Education Program).

\begin{tabular}{|c|c|c|c|c|c|}
\hline Participant & Age & Gender & Role & $\begin{array}{l}\text { Location/ } \\
\text { Title } 1\end{array}$ & Student disabilities \\
\hline P1 & 49 & Female & $\begin{array}{l}\text { Early childhood support coordinator - former special ed } \\
\text { preschool teacher }\end{array}$ & MD/Yes & Developmental delays \\
\hline P2 & 28 & Female & $\begin{array}{l}\text { IEP coordinator, former special ed. middle and high school } \\
\text { teacher }\end{array}$ & MD/No & Students with physical or developmental disabilities \\
\hline P3 & 37 & Female & Special ed. middle and high school teacher & MD/No & Students with physical or developmental disabilities \\
\hline P4 & 57 & Female & Caregiver of adult child, Special ed. teacher & MD/No & $\begin{array}{l}\text { Students with learning or emotional disabilities or } \\
\text { behavioral issues }\end{array}$ \\
\hline P5 & 50 & Female & Deaf Individual & TX/NA & $\mathrm{N} / \mathrm{A}$ \\
\hline P6 & 58 & Female & Special ed. IEP case manager & MD/Yes & $\begin{array}{l}\text { Students with Autism and/or intellectual and emotional } \\
\text { disabilities }\end{array}$ \\
\hline P7 & 51 & Female & Special ed middle school teacher & GAYes & Students with disabilities \\
\hline P8 & 39 & Female & Special ed middle school teacher & GAYes & Students with Autism and/or intellectual disabilities \\
\hline P9 & 57 & Male & Special ed coordinator middle school & GAYes & Students with disabilities \\
\hline
\end{tabular}

that she was different from other participants in that unlike other participants, she doesn't work in the formal special education space and has a disability. The majority of teachers work in Title 1 school that receive federal funding to serve primarily low-income families.

We enlisted personal contacts to identify and recruit participants. The special education professionals were from two different US regions: Central Maryland and Georgia. Participants with disabilities were from Texas. We chose participants in different parts of the US to capture a picture of how their experiences may be different or similar according to context. Figure 1 shows the chronology of our data collection. We started interviews in April as the schools were closing in the United States and continued until the beginning of the Fall school sessions. During this time, we managed to recruit nine participants and decided to stop recruitment since the educational, political and social landscape in the United States was shifting after September.

While the focus of our study was understanding the perspectives of special education professionals, we decided to include P5 who was different from other participants in that she did not work with children with disabilities and had a disability herself. We made this decision because she organizes presentations and workshops on accessibility education for adult participants, and so her perspective provides insight into a different but relevant aspect of how the pandemic impacted people with disabilities. While we asked her about her experience with learning technologies, she mostly provided input on her first-hand experiences as a deaf person and those of others in her community.

\section{Data Collection and Analysis}

We conducted semi-structured remote interviews over the phone or a web conferencing software (e.g., WebEx) that took on average $50 \mathrm{~min}$. Our protocol was reviewed and approved by our university's IRB office prior to data collection and all participants consented to participation. Participants received a \$25 gift card upon participation.

In the interviews, we asked participants about their background, including their experience with special education or accessibility, followed by their experience using assistive technologies in their practice or daily lives. Next, we asked them about their experience during the pandemic and any positive or negative experiences they wanted to share. We concluded with a few questions about their visions of the future in relation to the impact of the pandemic on accessibility and special education.

We designed and piloted our interview protocol within our research team before using it with participants. Following each interview our team met and discussed high level outcomes. We had built in flexibility in the interview protocol to have several sets of questions that we would choose from based on each participant's role. For example, we would ask teachers about their experience working with disabilities, while we would ask participants with disabilities both about their own experience using educational technologies, and their experience as educators. Figure 1 shows a general timeline including the timing of the interview in relation to changes in social distancing policies as they rippled through the United States.

We decided to conduct qualitative interviews because they provided us with flexibility to gather detailed information on participants' experiences and perceptions about a complex and dynamic subject. The nature of our questions and methodology reflect the ever-changing state of the pandemic. We decided to conduct semi-structured interviews (as opposed to online surveys or email questionaries) because they provide an opportunity to ask follow-up questions about topics that may have not been anticipated in the interview protocol (Lazar et al., 2017). Additionally, given the small number of participants, conducting interviews afforded an opportunity to conduct rich qualitative data.

We recorded and transcribed all interviews into verbatim transcription before using an inductive thematic analysis (Corbin and Anslem Strauss, 2014) to find themes and their interrelations in the data. Three members of the research team completed a first round of coding all data independently before reconciling their codes and identifying final themes with feedback from the fourth research team member.

\section{RESULTS}

Our analysis resulted in six themes that we will discuss in detail next. Figure 2 provides a thematic map of the identified themes. 


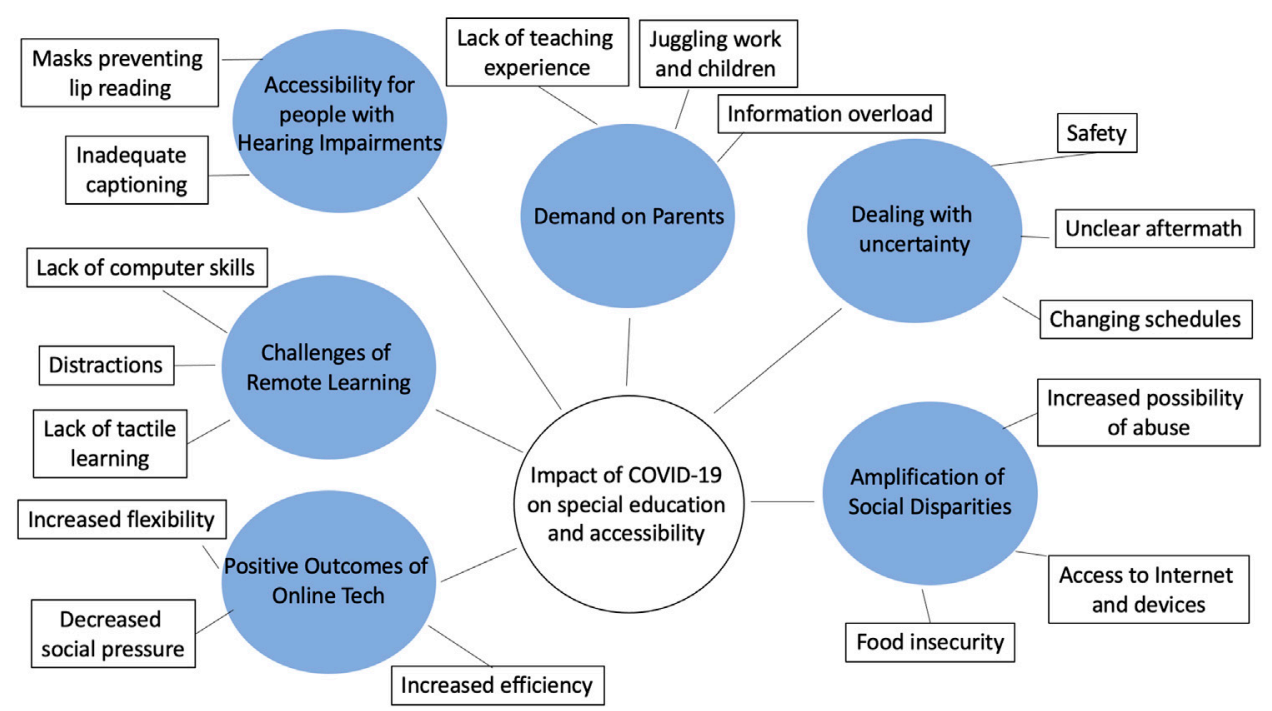

FIGURE 2 | A thematic map of the main theme and subthemes identified in the analysis.

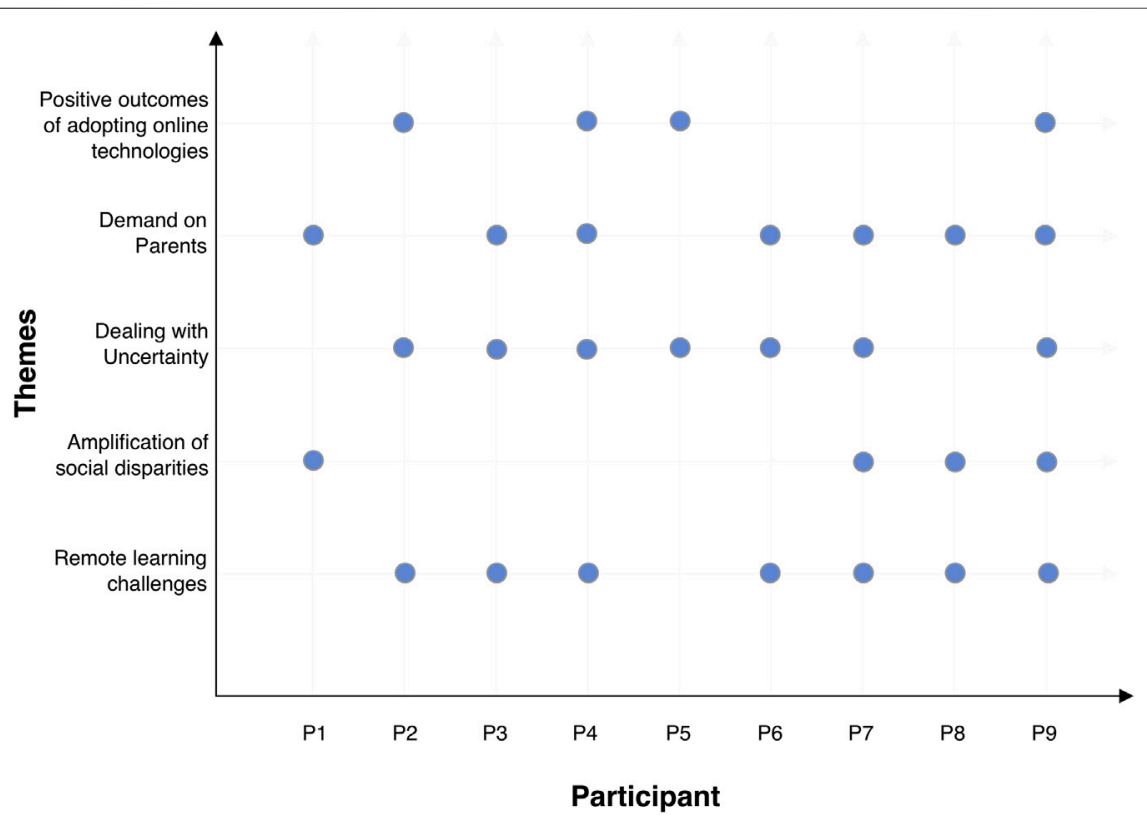

FIGURE 3 | A visualization of input from participants' data mapped to each theme.

Figure 3 provides a visualization of which participants' data mapped to each theme.

\section{The Challenges of Using Remote Learning Technologies}

The participants described several challenges related to the demands and limitations of using online remote platforms for learning. A key theme was the tactical limitations of remote technologies. As P2 stated, "quite a few of our students respond to and require tactile prompting." Participants also described how tactile objects, such as weighted blankets, can be used to help with comforting or emotional regulation of students and how not being able to use these objects makes remotely connecting with students with cognitive disabilities difficult.

The lack of physicality in remote learning also created a cognitive disconnect for some students between educational and home contexts. Some of the students showed signs of 
confusion about whether their fellow classmates and teachers are in their house. For example, P3 stated that "the parents ... gotten this understanding from their child that it's weird for them to see their teachers and classmates in their house .. 'No, they're just on the screen. They're not actually in your house."

All participants in special education (except P5) stated that their job was much harder during the pandemic because they could not see the students in person and actually interact with them. They all stated that they felt like they were missing something important by not being able to see the students in person. P8 described the difficulty of not being able to connect physically with students: "Because when you're there physically with somebody, you're able to kind of show them more and interact with them more on a physical level like, 'Okay. Look at me. Look at what my body is doing. Look at what my hands are doing.' You're able to do a lot more modeling of what your expectations are. And they're able to imitate your modeling. Easier than if you're doing it through the computer. So, we had more resources in the classroom. Because we had our manipulatives, our hands-on learning tasks and activities. And at home, they didn't have that."

Another issue was that the devices needed for online learning are expensive and easy to break. Access to devices and highbandwidth Internet had been limited. While many students received laptops from the school systems, there have been also many students who did not receive specialized devices because, as P1 stated "of where they were in the process, that they weren't at the place where they could be issue a device yet." P2, P4, P7, P8, and $\mathrm{P} 9$ all described initiatives at their schools to give laptops or tablets to students to help with online learning. For others, access to devices was more restricted.

Several participants also stated that they had issues with their students using the laptops or devices. Some of them, like P4, have students with a limited range of experience with digital devices, "some of them are really struggling because they don't know how to open two tabs at the top, things like that, basic computer navigation," even though, "they are very adept with their phones." P8 described one student who "would just run away from the computer because he didn't even use the computer in the classroom. He would break it. He'll bang onto the computer. He doesn't see it."

Others, like P7, have Internet connectivity issues, where "every student did not have internet." This meant that these students could not access online learning platforms, with some having limited access to computers. This issue persisted even in the presence of school-provided laptops (e.g., Chromebooks) because of other family members using them for other purposes, for example to find jobs.

\section{Amplification of Social Disparities}

Another key theme that emerged was how the pandemic amplified socioeconomic disparities in relation to children with disabilities. This theme was particularly prominent in data from P7, P8 and P9 who all resided in Georgia and were also interviewed later (July 2020) compared to other participants. All of these participants worked in Title 1 public schools that received federal assistance and serve students in low-income families. As P7 put it, “...we're talking very low, low, low income. I mean, maybe 10 people in a home living off of $\$ 15,000$."

P7 described some of the issues regarding access to resources and information as, "we have food insecurity. Large, large, large, large food insecurity problems... [Another issue] would be maybe access to the information such as if we're emailing a parent that can't speak English. Usually, at our school, we have translators. Well, you can't translate 6,000 emails that are going out."

In an attempt to overcome the economic and technical disparities, the Georgia district provided even before the pandemic laptop computers to all of the students. However, once the pandemic began the district realized that not all students had access to reliable Internet. As P7 described, "we have huge Internet issues. Our district provides computers to every student, so every student has a computer. However, every student did not have Internet ... so the kids that did have internet, we found if you had three to four to six kids by chance, they were all trying to access the Internet at the same time." The district had tried mitigating this issue by dividing up the time of day that children in different classes had to log into class to spread out the technical issues that need to be addressed to different times in the day. P7 stated, "so then our district went to different times of day for different ages of students to try to help with that, which I thought was pretty smart. So elementary kids were responsible for logging on at 8:00am till about 11:00am. Middle school students could log on between 10:00am and 2: $00 \mathrm{pm}$. And then high school students would supposedly log on between noon and 4:00pm or 5:00pm in the evening . . because everybody at the beginning was told to log on at 8 o'clock. So, everybody, all 27,000 of our students plus their parents plus anybody else at home with computers, we're all trying to access at 8 o'clock ... That was not good."

While effective to some extent, access to devices and the Internet did not overcome disparities. For example, another related issue was control over who used the school-provided computer and Internet in the home. P7 described, "Okay, let's say there's two computers at the house and eight people need to be on them this Fall, let's say. The dad is looking for a job, mom has to $\log$ in, they're using the kid's computer. Who's going to take preference? Of course, it's the adults..." P9 pointed out that in cases where a parent was at home and prioritizing the child accessing the computer to do schoolwork, "they sit with their child almost about all day long trying to help them do the work. And without the skillsets that have been taught through years of experience in the school building and brought from a college perspective, it's hard, it's very difficult to meet that need." $\mathrm{He}$ further explained that it was even more of an issue for special education students with "adaptive needs": "You know, we were talking about our students with adaptive needs? It was not successful. I mean, no matter how many computers you put in front of them, or how many different programs you find, it's not the same as having that child in the classroom."

As the pandemic progressed, other serious issues started to arise. According to P7, the county sheriff's department put out a release stating that domestic abuse incidents were on the rise. She described how this negatively impacts children: "School is their refuge and no longer are they able to come to school. So, they may 
not be the victim of the abuse but listening to it, seeing it day after day. And then you're telling them to stay in the house because there's a pandemic."

Two of the Georgia teachers reported that student attendance dropped. P7 stated, "We were getting very low turnout to our classes. And though I teach 38 kids sometimes I'd see four in a week." P8 who taught a self-contained class for special education students who all had adaptive needs stated that only one of her five regular students completed most of their assignments. "Two of them actually didn't log in to Zoom at all ... [With another student] I never got to see him through Zoom but assignments were getting completed and they were getting turned in like at 11: 00 at night ... I didn't really get to interact with him at all."

\section{Demand on Parents}

Most of our participants underlined the important role of parents during the pandemic and how they were adversely impacted by it. For example, P1 describe how parents, "will always be there ... that's the person you want to feel successful and feel that they have the strategies and the tools and the resources to help their child." Participants described how during the pandemic, parents not only shouldered the burden of taking care of children at home, but also stepping in as teachers, all the while often working full time and managing their own stress. P9 stated, "the biggest thing I have heard from a lot of our parents are, 'I don't have the time to sit with my child and help them like the teachers do at school." This need for parents to help children log in to classes, manage computer access, and even help with developing lesson plans, put a lot of additional demand on them, demands that may also be incompatible with them performing at their jobs or taking care of multiple children.

Participants described how they observed parents being flooded with information and resources, which can be helpful, but also, as P7 described, the increased amount of information may be "too overwhelming for them to access" mentally. P7 also described how parents are often charged with providing children with the means of accessing online classes and lessons, "because everything needs a code and access password."

While all parents may face information overload and increased need for their constant interaction with their children due to the pandemic, participants described that these were amplified for the parents of children with disabilities who suddenly had to step in with special education. P6 described how parents were often creative but that ultimately, "it's very hard on them. They often don't have the skillset for it." Teachers also described having difficulty in making sure that parents were able to assist their students in attaining their goals because they were not in their students' home in person, and sometimes had limited interactions through remote communication. For example, P8 said, "I don't know if Mom is sitting with him. She says she's working with him, but then you wonder, are they just doing it to get it done."

\section{Dealing with Uncertainty and Shifting Perspectives}

Participants described how a lack of certainty and planning created stress for teachers, parents and students. Before the pandemic, many teachers had attended trainings for handling different crisis scenarios, however, none of them had prepared them for the particular characteristics of the pandemic, including its ongoing nature and the shift quick shift to distance learning. P4 stated that "there's all kinds of emergency preparedness, planning kind of stuff ... come up with their emergency plan in case we have an active shooter or something like that. And so, they go through these kinds of scenarios. And this distance learning scenario definitely should be one of those scenarios." P6 described that "a lot of the systems that we set up [in response to the pandemic], we set up without any time to plan." Several participants described how there is need to plan better for similar occurrences in the future, since crizes happen again at some point. P9 said "we, as the education field, need to have something in place if this ever happens again or continues in the world [direction] we're going."

Participants described how a lack of certainty and planning created stress for teachers, parents and students. Participants described that none of the trainings they had attended previously had prepared them for facing the COVID-19 pandemic. Several participants stated that the constant changing of policies has been hard to adapt. P2 stated, "I do feel like the state was, just from my personal experience, not prepared for this. It's been a month and a half now and every single day there's new changes to policy and things like that. And it just seems like everyone's scrambling to come up with the right answer, but everyone has different answers. So, it just doesn't feel as organized as we would hope." P6 also described that some reflection on the policies might be needed, "I think if we could sort of embrace some of these policies and take some time to look at them and say, "What's working? What's not working?" so that we would have some emergency pathways in the future, I think would be very smart." Some participants were concerned about the environment for when students and teachers go back to in-person learning. For example, P3 stated "Right now we've furloughed a lot of staff ... So my fear is that when we go back, some of them might not return. And I feel like that we need to plan for if it were to happen again, what we can do to keep them involved and how they are able to better support the students."

With regards to communication between parents and caregivers, P4 described challenges in clearly but kindly describing what is going on to children with cognitive disabilities: "She [adult autistic daughter] can't verbalize how much she knows that's going on, but she knows stuff is going on. I don't think she knows it's germs that are out there that are going to give you these symptoms. And your dad and I have been very careful in terms of expressing our anxiety around her, but she knows something's happening."

\section{Positive Outcomes of Adopting Online Technologies}

When asked about any positive outcomes that may have resulted from the experience of social distancing or remote special education, participants identified that some of their students preferred the online mode and that this mode can also lead to increased efficiency in some cases. For example, P2 stated how 
she and some of her colleagues found it more efficient to conduct activities online: A "we really can do more with online learning ... if we're doing a vocabulary lesson, instead of printing out pictures of the words and laminating them and all that and having those resources, we could instead put it on the smart board or the iPad. And it's a lot of time saving and resource saving."

Interacting with others in person can often be challenging for many children with autism or other developmental disorders, and P4 described how some students are preferring the online learning, "some of them [students] are doing really well because they can just interact through the computer ... Some of them are like, "I like this distance learning stuff. I don't have to talk to anybody." On the other hand, some of the students reacted negatively to being on remote video. For example, P8 described how one of her students "is not into the camera, doesn't like to look at herself in the camera, does not like to take pictures. So she only logged into Zoom one, maybe two times and of those two times, she did not have her camera on and did not speak a lot compared to what would have been in the classroom where she is one of my most verbal in the classroom and very willing to talk and volunteer."

Finally, P9 described how some of the flexibility with programming that was experienced during the pandemic may inspire future hybrid learning models: "I think what we've done since March is probably going to change the way we approach the way students are educated. I think we may see where we're doing things more virtual. There may be a time where we're doing three days in brick and mortar and two days virtual. Or there may be a time where we're setting up with students who may not do well in the morning and have a teacher that teaches from noon to six in the evening or something and they do it all virtual .... Use it as a way to reach students who maybe don't do so well in a brick and mortar building that maybe they have - I don't know - different environments that they live in and they do better at home or they do better from a different setting or a smaller setting or something. ... Yeah. I think it's going to become more of a norm than more of an emergency situation, I guess."

\section{Accessibility Issues for People with Hearing Impairments}

One of our participants, P5, who is deaf described several accessibility challenges that people with hearing impairment faced during the pandemic. For example, she described how people with hearing impairments rely on lip reading to understand what other people are saying. She described how "even with my hearing aids on ... I have to lip read for understanding." "Everybody will be wearing masks ... I would be lost with all the masks."

Another issue P5 identified was related to the increased need to use smartphones to access services. She stated that these phones often have inadequate captioning software which causes issues when using curbside pickup services: "My friend ... she went to pick up an order from a bakery. They don't have a drive-thru, so what you're supposed to do is drive up there and call them. She can't call them. I can't call them."
Finally, relying on video chat for remote meetings can be challenging because people with hearing impairments often look at the captioning that is generated automatically and not make eye contact with their colleagues. P5 described a scenario, "there was just a guy ... he feels like it's hard for deaf people, because if they're reading the captions, they're looking down... And he was saying, because deaf people have to look at the captions, it's taking away...because he pointed to a study that said the problem with these video calls is lack of eye contact."

\section{DISCUSSION}

Our findings provide a troubling picture of the impact of the COVID-19 crizes and its aftermath on special education and accessibility. In this section, we present three priorities that emerged based on a synthesis of our findings.

Ensuring continued learning in the face of inequity: In line with concerns reported in the news and in previous research (Dailey and Starbird, 2014; States News Service, 2020), our findings show that the COVID-19 pandemic and measures instated in response to it, amplified existing social inequities. Our participants shared with us accounts of increased chances of exposure to poverty, violence and even abuse in the face of the pandemic for individuals with disabilities, and further described how the adoption of new measures, for example, video-based remote learning technologies and masks, may introduce new barriers to access for individuals with disabilities. While decreases in student productivity was reported in all cases, these were more severe in the case of Title 1 schools, where other issues such as lack of food security or access to translation services were also observed. In the face of these issues, children must stay connected to their support system (i.e., schoolteachers, counselors, etc.) even while at home. Furthermore, response planning needs to take into account factors that may impact diverse individuals and communities differently and consider employing equity-based strategies that while efficient, take into account the perspectives of diverse people. In future work, it would be worthwhile to explore how approaches such as Universal Design (UD) (Gjøsæter, Radianti and Chen, 2018) may be adapted and drawn on to ensure design decisions speak to the needs of as many people as possible.

Prioritizing children's well-being and confidence: Some of our participants (P7, P8, and P9) described intersecting issues faced by the children and families they serve, in which socioeconomic factors or lack of access to information infrastructures, such as broadband Internet access, had amplified issues of equity and participation. These concerns were mostly voiced by participants who we interviewed later in the course of the pandemic (as shown in Figure $\mathbf{1}$ and Figure 3) and were serving low-income populations in Georgia through Title 1 schools. Therefore, they may be more pressing for these families that have been facing uncertainty over a long period. Previous research has shown that gaps in school readiness and later achievement 
are linked to poverty and social and economic inequality (Blair and Cybele Raver, 2015). Furthermore, reduced access to learning experiences during formative periods of children's life may compromise their long-term learning abilities through poorly developed verbal and social skills (Lazar et al., 2017).

Our participants also described how they cared not only about their students' learning experiences but also their mental and physical well-being. Along with covering the school curriculum, they described how they take special care that students receive personal attention and feel motivated. At school, children have access to assistive technology, internet, food, and a sense of security which helps them focus on academic work. Participants described how the pandemic disrupted access to these resources for their students, in addition to strictly learning resources. The teachers also described how they in face-to-face learning they rely heavily on body language, facial expressions and touch to communicate with their students. This method of communication has been difficult to replicate virtually, negatively influencing students' confidence.

Our findings point to a need to develop a holistic view of the experiences of children with disabilities during a crisis and is aware of other factors, such as socioeconomic status, when developing strategies for support. Additionally, it underlines the importance of systematically studying what is needed for an intervention to equitably and sustainability work. Since implementing online learning effectively involves creating an environment conducive to learning in students' homes, it would be helpful if teachers or administrators could occasionally check-in with families or even visit students' homes to see if they have what they need to participate in learning. We appreciate that this recommendation would require increased resources or provisions, for example, to ensure the privacy of students and their families. However, even implementing it on a small scale can provide insight on what are the minimum conditions for effectively participating in learning remotely for students with disabilities.

Using appropriate communication mechanisms with families: Many of our participants described how families, and caregivers, in particular, were overwhelmed with information and updates about the ongoing pandemic, and at the same time had difficulty locating the latest updates. Parents were receiving many types of information, including COVID-19 updates, information about school procedures, and assignment due dates. While different types of information, including COVID-19 updates, school procedure alerts and assignment due dates, may have been relevant, they were not all important, time-sensitive, or useful to the same extent. Our participants recommended considering using different communication channels to distinguish between different types of information. For example, sending text messages about important items that needed immediate attention or response seemed more effective and can be leveraged in the future. This situation calls for more attention to developing streamlined and consistent sources of information that parents may access through a communication channel that works for them (e.g., text, email, etc.).

\section{CONCLUSION}

Crizes by definition take us by surprise and we find it important to capture diverse experiences and perspectives, as long as conducted ethically, as early and as frequently as possible, such that insights that may be present at the moment are not lost. It has been our intention in this exploratory research study to contribute to a snapshot of the experiences of special education professionals during the early phases of the COVID-19 pandemic. Our research has shown that we need to have stronger practices in place to ensure that during future crizes, learning is continued in the face of inequities, children's wellbeing and confidence are prioritized, and appropriate communication mechanisms are used to keep families informed. We wish that our findings and lessons learned will lead to more informed future planning that takes into account the needs and desires of people with disabilities, their families, and the professionals working with them.

Limitations of our work include the small number of participants who are all situated in the United States. Furthermore, we did not include the perspectives of children with disabilities and their parents, partially because we wanted to focus on population-level insights from experts who work with multiple individuals and families. Additionally, we wanted to reduce the burden of participation for the families of children with disabilities during this difficult time. Future work can investigate the perspectives of a larger number of participants situated in different contexts and compare and contrast their experience with our participants and each other. Our study has also taken a broad lens by looking at disability and special education as a whole. Future research can focus on specific populations, for example children with cognitive disabilities or older adults, and report on their experiences. Finally, future collaborative studies that compare the experience of special education professionals and educators outside of the United States would provide further insights and complement our current study well. We also plan to investigate the perspectives of parents and children with disabilities.

\section{DATA AVAILABILITY STATEMENT}

The original contributions presented in the study are included in the article/Supplementary Material, further inquiries can be directed to the corresponding author. 


\section{ETHICS STATEMENT}

The studies involving human participants were reviewed and approved by UMBC Institutional Review Board (IRB). The patients/participants provided their written informed consent to participate in this study.

\section{AUTHOR CONTRIBUTIONS}

FH contributed to the conception and research design of the study. EL, SV, and SG contributed to the data collection, analysis and writing of the draft. EL and SG wrote the Materials and Methods and Results sections of the paper and SV created the figures. FH wrote the Introduction, Related Works and Discussion of the paper. All

\section{REFERENCES}

Al-Mouh, N. A., Al-Khalifa, A. S., and Al-Khalifa, H. S. (2014). "A first look into MOOCs accessibility," in International conference on computers for Handicapped persons (Cham: Springer), 145-152.

Blair, C., and Cybele Raver, C. (2015). School readiness and self-regulation: a developmental psychobiological approach. Annu. Rev. Psychol. 66, 711-731. doi:10.1146/annurev-psych-010814-015221

Birnbaum, M. L., Daily, E. K., and O'Rourke, A. P. (2015). Research and evaluations of the health aspects of disasters, Part III: framework for the temporal phases of disasters. Prehosp. Disaster Med. 30 (6), 628-632. doi:10.1017/S1049023X15005336

Chatterjee, R., Juvale, D., and Jaramillo Cherrez, N. (2017). "A MOOC for U: the design of a MOOC based on universal design for learning," in Society for information technology \& teacher education international conference, 143-148.

Corbin, J., and Anslem Strauss, A. (2014). Basics of qualitative research: techniques and procedures for developing grounded theory. Thousand Oaks, CA: Sage Publications.

Dailey, D., and Starbird, K. (2014). Journalists as crowdsourcerers: responding to crisis by reporting with a crowd. Comput. Support. Coop. Work, 23 (4), 445-481. doi:10.1007/s10606-014-9208-z

Gjøsæter, T., Radianti, J., and Chen, W. (2018). "Universal design of ICT for emergency management," in International conference on universal access in human-computer interaction. 2018, 63-74.

Gleason, C., Valencia, S., Lynn, K., Wu, J., Guo, A., Carter, E. J., et al. (2020). "Disability and the COVID-19 pandemic: using twitter to understand accessibility during rapid societal transition," in Proceedings of the conference on computers and accessibility (ASSETS '20), Article 5, 1-14.

Hughes, A. L., and Palen, L. (2009). Twitter adoption and use in mass convergence and emergency events. Int. J. Emerg. Manag. 6 (3-4), 248-260. doi:10.1504/ ijem.2009.031564

Iniesto, F., McAndrew, P., Minocha, S., and Coughlan, T. (2019). "Auditing the accessibility of MOOCs: a four-component approach," in European conference on technology enhanced learning (Cham:Springer), 650-654.

Jagger, J. C. (2011). "Neighbors helping neighbors: the disability community and emergency preparedness," in Crisis as an opportunity: organizational and community responses to disasters. (Lanham, MD: University Press of America), Vol. 80.

Kim, S. J., and Bostwick, W. (2020). Social vulnerability and racial inequality in COVID-19 Deaths in Chicago. Health Educ. Behav. 47 (4), 509-513. doi:10. $1177 / 1090198120929677$

Lazar, J., Feng, J. H., and Hochheiser, H. (2017). Research methods in humancomputer interaction. Burlington, MA: Morgan Kaufmann.

Lord, J. E. (2010). "Disability-inclusive disaster preparedness and response: challenges and opportunities for reconstruction in Haiti," in Proceedings of the ASIL annual meeting, Vol. 104, 118-122. authors contributed to manuscript revision, read, and approved the submitted version.

\section{FUNDING}

This work is partially supported by the National Science Foundation under Grant No CNS-2030451.

\section{ACKNOWLEDGMENTS}

We would like to thank our participants for their time and insights.

Morris, J. T., Mueller, J. L., and Jones, M. L. (2014). Use of social media during public emergencies by people with disabilities. West. J. Emerg. Med. 15 (5), 567-574. doi:10.5811/westjem.2014.4.21274

National Council on Disability (2005). Saving lives: including people with disabilities in emergency planning. April 15, 2005. Available at: https:// asksource.info/resources/saving-lives-including-people-disabilities-emergencyplanning (Accessed October 8, 2020).

National Council on Disability (2020). The impact of hurricanes katrina and rita on people with disabilities: a look back and remaining challenges. August 6, 2006. Available at: https://ncd.gov/publications/2006/aug072006 (Accessed October 8, 2020).

Palen, L., Anderson, J., Bica, M., Castillos, C., Crowley, J., Diaz, P., et al. (2020). Crisis informatics: human-centered research on tech \& crises: a guided bibliography developed by crisis informatics researchers.

Roberts, J. B., Crittenden, L. A., and Crittenden, J. C. (2011). Students with disabilities and online learning: a cross-institutional study of perceived satisfaction with accessibility compliance and services. Internet High Educ. 14, (4), 242-250. doi:10.1016/j.iheduc.2011.05.004

Shapiro, E., and Harris, E. A. (2020). This is schooling now for 200,000 N.Y.C. Children in special education. New York Times, April 16th, 2020. Available at: https://www.nytimes.com/2020/04/16/nyregion/special-education-coronavirus-nyc. html (Accessed October 8, 2020).

States News Service (2020). Empowering students with disabilities during the COVID-19 crisis. Gale in Context: Biography. Available at: https://link.gale. com/apps/doc/A627378636/BIC?u=umd_umbc\&sid=BIC\&xid=3dc9b96a (Accessed October 8, 2020).

U.S. Department of Justice, Civil Rights Division (2008). Making community emergency preparedness and response programs accessible to people with disabilities. October 9, 2008. Available at: http://www.ada.gov/ emergencyprepguide.htm (Accessed October 8, 2020).

Xiong, J., Lipsitz, O., Nasri, F., Lui, L. M. W., Gill, H., Lee, P., et al. (2020). Impact of COVID-19 pandemic on mental health in the general population: a systematic review. J. Affect. Disord. 277, 55-64. doi:10.1016/j.jad.2020.08.001

Conflict of Interest: The authors declare that the research was conducted in the absence of any commercial or financial relationships that could be construed as a potential conflict of interest.

Copyright $\odot 2021$ Long, Vijaykumar, Gyi and Hamidi. This is an open-access article distributed under the terms of the Creative Commons Attribution License (CC BY). The use, distribution or reproduction in other forums is permitted, provided the original author(s) and the copyright owner(s) are credited and that the original publication in this journal is cited, in accordance with accepted academic practice. No use, distribution or reproduction is permitted which does not comply with these terms. 